\title{
Review Article Decreased Mortality of falciparum Malaria in Anemic Prisoners of War?
}

\author{
George Dennis Shanks* \\ Australian Defence Force Malaria and Infectious Disease Institute, Enoggera, Australia; School of Public Health, University of Queensland, \\ Brisbane, Australia
}

\begin{abstract}
Modern clinical trials have suggested that anemia protects against malaria mortality. Military records of the Second World War in Asia were examined to see if there was support for this hypothesis. When relatively well-nourished Imperial Japanese Navy sailors captured on Nauru $(n=799)$ were imprisoned on the Fauro Islands, $26 \%$ died from falciparum malaria. Similarly treated but very malnourished colocated Imperial Army soldiers experienced low stable malaria mortality. One-fifth of previously healthy Australian Army soldiers $(n=252)$ retreating from New Britain died largely because of malaria in April 1942. Malnourished prisoners of war, who were as a group very anemic, both Australian Army soldiers in Thailand and Japanese Army soldiers in Papua New Guinea, had high malaria rates but very low $(<3 \%)$ mortality rates. Malaria immunity does not adequately explain this dichotomy, suggesting that severe nutritional deprivation may be protective against malaria mortality possibly because of iron-deficiency anemia.
\end{abstract}

Most persons infected with falciparum malaria survive even when given suboptimal chemotherapy. Many genetic polymorphisms of the erythrocyte (e.g., thalassemia and ovalocytosis) which produce some degree of anemia have been selected evolutionarily by increasing host resistance to otherwise lethal Plasmodium infection. Analyses of large numbers of severe malaria patients treated during controlled chemotherapy trials indicate that moderate anemia may be protective against death although the pathophysiology of such a putative effect is unknown and may be confounded by multiple factors such as duration of infection. ${ }^{1,2}$ Despite very high malaria attack rates, Second World War soldiers only rarely died of falciparum malaria even under extraordinarily adverse conditions such as those experienced by prisoners of war (POW). ${ }^{3}$ In the Australian military experience during 1941-1945, only two specific instances of extraordinary mortality due to malaria were observed: Australian Army soldiers retreating from Rabaul, New Britain, in April 1942 and Imperial Japanese Navy POW who had been transported from Nauru to Fauro Islands in October $1945 .{ }^{4}$ As both episodes occurred within the context of thousands of both Australian and Japanese POW with very low mortality rates due to malaria, contemporary records were examined to determine if some explanation could be found for this dichotomy. ${ }^{5-8}$

A Japanese Imperial Navy (IJN) Special Landing Force occupied Nauru and Ocean Islands in August 1942 to secure the phosphate mines. The Japanese forces on Nauru did not participate in combat operations, although they were subject to air raids and largely cutoff from regular supplies. ${ }^{9}$ Despite severe food limitations forced on the local population by military controls, the health of the Japanese garrison at surrender was reported to be good, with only $1 \%$ classified as hospital cases because of illnesses such as dysentery, tropical ulcers, and avitaminosis. No acute cases of malnutrition were noted in either the Japanese sailors or their Korean workforce. ${ }^{5,6} \mathrm{Be}-$ tween October 1-3, 1945, the Japanese military were taken *Address correspondence to George Dennis Shanks, Australian
Defence Force Malaria and Infectious Disease Institute, Weary Dunlop
Dr., Gallipoli Barracks, Enoggera 4051, Australia. E-mail: dennis. shanks@defence.gov.au aboard Allied ships initially to Bougainville and then arrived in POW camps in Fauro Islands on October 30-31.

No malaria exists on Nauru because of lack of anopheline vectors, so the IJN POW from Nauru had no recent experience with malaria unlike other prisoners coming from different parts of Papua New Guinea (PNG). An epidemic soon occurred in 799 IJN personnel from Nauru, resulting in 530 being hospitalized for malaria treatment by November 26 with 212 (26.5\%) malaria deaths recorded by December $5 .{ }^{4}$ The 24,000 Japanese prisoners on Fauro were equally distributed between Army and Navy personnel with the all-cause mortality shown in Figure 1. Although malaria was widespread on Fauro before arrival of prisoners from Nauru (192/1,000 men), mortality was largely limited to the two (of 15 total) camps housing IJN personnel from Nauru. All-cause mortality in Imperial Japanese Army (IJA) prisoners did not change, and the ratios of Navy/Army mortality rose from $<1$ to 18 within 3 weeks and remained $>3$ at the end of $1945 .{ }^{4-6}$ Equivalent medical care was provided by both IJN and IJA military medical personnel to their own POW supervised by Australian officers (Supplemental Figure 1), and there were no limitations on antimalarial drugs supplied by the Allies. ${ }^{9}$

Japanese POW in IJA (92/1,000) and IJN $(105 / 1,000)$ components had equivalent malaria rates on August 31, 1945 at surrender on Bougainville. Contemporaneous records from similar populations in the region demonstrated that larger POW camps $(n=90,000)$ in Rabaul, $500 \mathrm{~km}$ northeast of Fauro, had malaria rates of 75/1,000 in Japanese POW while colocated, but by then, released Indian POW malaria rates were 49/1,000. There were another 12,000 IJA POW on New Ireland whose all-cause mortality rates were $<1 \%$ over 4 months. ${ }^{5}$ The worst overall mortality was in IJA POW who had surrendered in PNG near Wewak and then imprisoned on Muschu Island; these soldiers were the minority who had survived the previous year of arduous campaigning largely cutoff from any military or food supplies. In the first 2 months following surrender, $5.4 \%$ of 13,000 POW on Muschu Island died with another $1.8 \%$ mortality in months $3-4 .{ }^{6}$ Largely, these deaths were due to extreme malnutrition complicated by a variety of tropical infections including malaria. Figure $2 \mathrm{~A}$ shows a comparison of the medical problems seen in the Japanese POW military hospitals on both Muschu $(1,156$ 


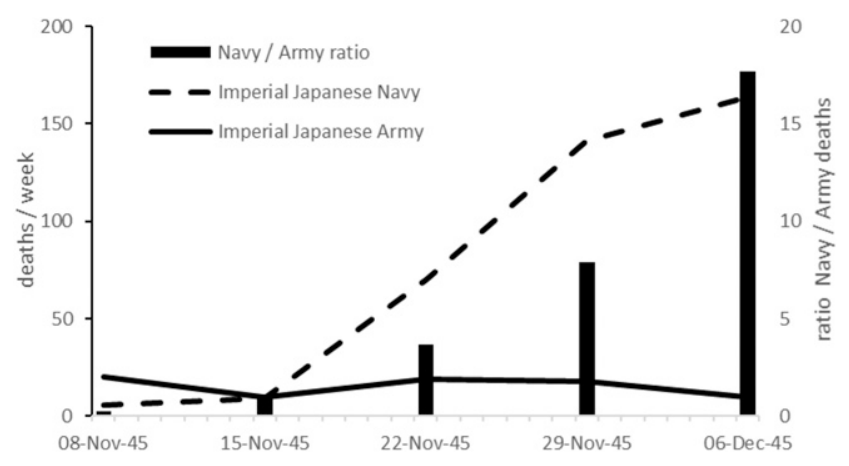

Figure 1. Weekly all-cause mortality in Imperial Japanese prisoners of war held by the Australian Army in the Fauro Islands south of Bougainville, Papua New Guinea, in November 1945. The total number of prisoners was about 24,000 spread through 15 camps and was roughly equally distributed between those in the Army and Navy. ${ }^{5}$

patients) and Fauro Islands (1,642 patients) at the time IJN POW arrived from Nauru in early November 1945. It is clear from administrative reports that the IJN POW from Nauru had been much better fed than the extremely malnourished prisoners on Muschu Island, but no objective measurements were recorded. ${ }^{5,6}$
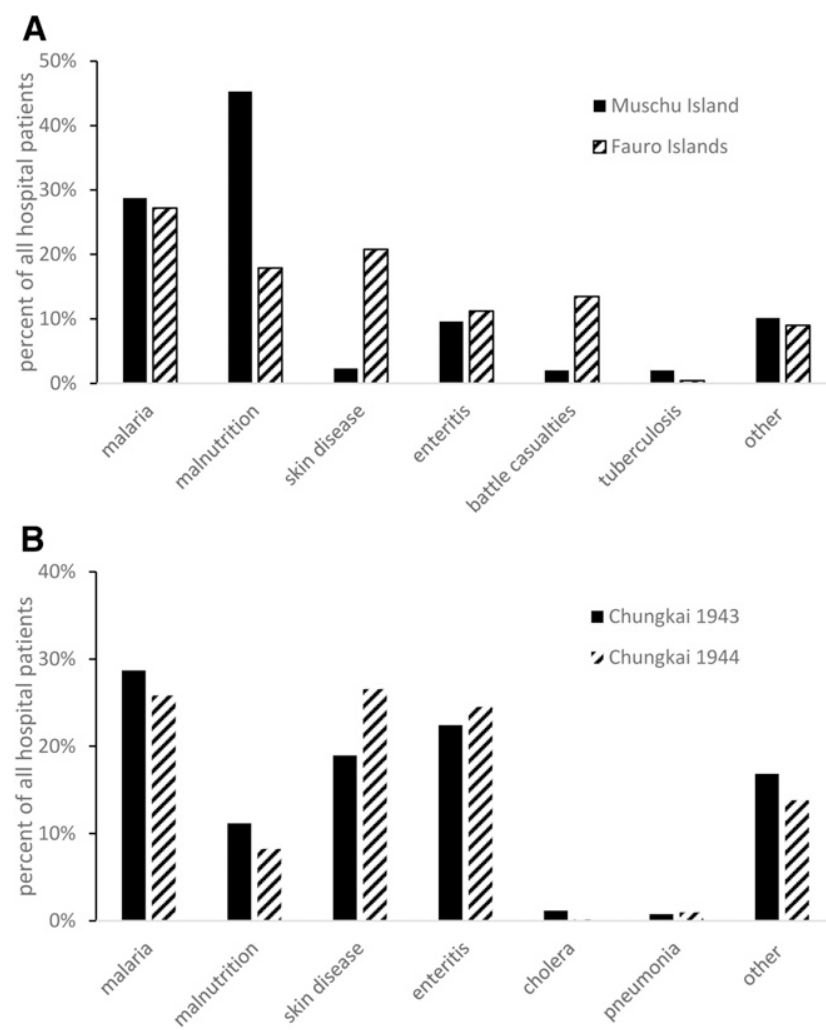

FIGURE 2. Relative proportions of medical causes of hospitalization. $^{6}$ (A) Hospitalized Imperial Japanese prisoners of war (POW) held by the Australian Army on two separate islands of Papua New Guinea in early November 1945 . Muschu Island $(n=1,156)\left(3.4177^{\circ} \mathrm{S}\right.$, $\left.143.5960^{\circ} \mathrm{E}\right)$ is north of Wewak, whereas Fauro Islands $(n=1,642)$ $\left(6.2146^{\circ} \mathrm{S}, 155.6325^{\circ} \mathrm{E}\right)$ are $1,400 \mathrm{~km}$ southeast near Bougainville. (B) Hospitalized Australian Imperial Force POW held by the Japanese Army at Chungkai, near Kanchanaburi, Thailand $\left(14.0058^{\circ} \mathrm{N}\right.$, $\left.99.51513^{\circ} \mathrm{E}\right)$, during both $1943(n=11,572)$ and $1944(n=6,793)$ during the period of the railway construction. ${ }^{8}$
The Fauro epidemic of lethal malaria at the time was directly compared with the previously healthy Australian Army soldiers of the 22 Infantry Battalion who escaped in February 1942 from the Japanese invasion of Rabaul and marched across New Britain to eventual evacuation 2 months later. Despite initial suppression by variable amounts of oral quinine, 50/252 (19.8\%) died from falciparum malaria. ${ }^{4}$ By contrast, < 100 other Australian soldiers who were not POW died of malaria during the entire Second World War, with a case fatality rate $\ll$ $1 / 1,000 .{ }^{10}$ Such low mortality rates indicate a well-functioning military medical system with sufficient antimalarial drugs; however, malaria mortality rates were also very low in Australian soldiers under severe physical and nutritional stress in POW camps in Thailand. ${ }^{7,8,11,12}$

In 1943 3,336 severely ill malaria patients were hospitalized as Allied POW in Chungkai, Thailand, but only $2.0 \%$ died compared with a $10.7 \%$ all-cause hospital mortality. Despite continuing extreme nutritional stress during railway construction, in 1944, case mortality actually decreased to $0.7 \%$ in 1,753 malaria patients treated at the same hospital. ${ }^{8}$ The relative distribution of patients at the Chungkai is shown in Figure 2B. More than 2,000 malaria patients were treated in other nearby POW hospitals in 1943 without a single recorded death. This remarkably low malaria mortality in POW was reproduced in $>1,000$ severely ill, malnourished Allied POW, given intravenous quinine for malaria in Singapore 1942-1944 as was published after the war's end. ${ }^{13}$ When the Australian Army POW records were examined at the end of the Second World War for the purpose of war crime tribunals, relatively few deaths of the severely malnourished prisoners $(n=3,087)$ were directly attributed to malaria $(4.3 \%) .{ }^{3}$ Severe anemia was also a major problem at Chungkai Hospital necessitating a large blood transfusion clinic (100 transfusions/month) despite the primitive apparatus available. The indication for transfusion was $<2.5$ million red blood cells $/ \mathrm{mm}^{3}(\approx 7 \mathrm{gm} / \mathrm{dL})$; blood donors were only required to have a hemoglobin of $>10$ $\mathrm{gm} / \mathrm{dL}$, which was estimated to be considerably higher than that of most of POW. ${ }^{14}$

In Table 1, the four populations described are roughly compared. The unexplained dichotomy therefore becomes the extreme mortality (20-26\%) seen in Japanese POW from Nauru and Australian soldiers from New Britain who had been previously relatively healthy compared with their contemporaneous compatriots who had endured extreme privation, particularly malnutrition, with much lower malaria mortality rates $(\approx 1 \%)$. Medical care and quality of antimalarial drugs are unlikely to provide simplistic answers as other Japanese POW were not dying at high rates of malaria on Fauro despite treatment by the same medical officers using the same drugs. Although there were few scientific studies carried out on Japanese POW, anemia was found in a majority of those studied, confirming observations in Allied POW. ${ }^{15}$ Other limitations inherent in these data collected during war from fragmentary records in the POW camps include uncertainty as to the degree of malnutrition or anemia in the prisoners as well as uncertainty regarding diagnoses of malaria and malnutrition.

It is possible that malnutrition and specifically anemia were partially protective against mortality due to malaria although one cannot distinguish what particular deficiency (e.g., calories and micronutrients) might have been specifically involved. Iron supplements given to entire populations have in some cases been shown to increase mortality in children in malaria-endemic 
TABLE 1

Comparison of different Japanese and Allied military and POW groups described in the text noting that the more malnourished groups had remarkably lower malaria mortality

\begin{tabular}{|c|c|c|c|}
\hline Population & Nutritional status & Malaria incidence & Malaria mortality (\%) \\
\hline $\begin{array}{l}\text { Imperial Japanese Navy POW from } \\
\text { Nauru }\end{array}$ & $\begin{array}{l}\text { None hospitalized for malnutrition unlike } \\
\text { IJA POW }\end{array}$ & $\begin{array}{l}\text { None until arriving in POW camps in } \\
\text { PNG }\end{array}$ & 26 \\
\hline IJA POW from PNG & $\begin{array}{l}\text { Severely malnourished and likely very } \\
\text { anemic }\end{array}$ & $\begin{array}{l}\text { Infection near universal, clinical disease } \\
\text { common }\end{array}$ & $<3$ \\
\hline Australian soldiers from Rabaul, PNG & Well nourished, not known to be anemic & Undocumented, but likely universal & 20 \\
\hline Allied POW in Thailand/Singapore & $\begin{array}{l}\text { Moderate to severely malnourished and } \\
\text { most were anemic }\end{array}$ & $\begin{array}{l}\text { High in those returning from camps in } \\
\text { Thailand, little malaria transmitted in } \\
\text { Singapore }\end{array}$ & $<3$ \\
\hline
\end{tabular}

$\mathrm{IJA}=$ Imperial Japanese Army; PNG = Papua New Guinea; POW = prisoner of war. There were many POW camps and great pressure to repatriate POW at the end of the war in 1945 , resulting in very imprecise and fragmentary medical data. What is shown are rough estimates based on complied published and unpublished records.

regions. ${ }^{16}$ Transfusion of erythrocytes in children with mild malaria anemia (Hemoglobin 7-9.9 g/dL) actually resulted in more deaths than those randomized not to receive transfusion during a large clinical trial in East Africa. ${ }^{17}$ Further investigations by the same group have found that increasing transfusion volumes (from 20 to $30 \mathrm{~mL} / \mathrm{kg}$ ) in sick African children with fever increased the 28-day mortality by nearly 2 -fold, an effect not seen in those without fever. ${ }^{18}$ Most recently, moderate anemia has been shown to be one of the few factors from a large collection of controlled malaria chemotherapy trials that appeared to protect against death., ${ }^{1,2}$

Is some degree of anemia therefore related to the mortality dichotomy observed in POW malaria mortality? Host factor(s) seem to be the only viable explanation implying either unknown immune aspects or nutritional deficiencies likely focused on anemia. Neither the Japanese sailors on Fauro nor Australian soldiers on New Britain who suffered severe malaria mortality would have been malaria experienced/ immune. Malaria immunity cannot be directly measured, whereas anemia certainly was present in a great majority of POW. Given the modern clinical trial analyses suggest that moderate anemia is protective and transfusions in some cases may be detrimental when treating severe malaria, anemia would appear to viable hypothesis even if any mechanism remains speculative. Clinical observations made under extraordinarily difficult conditions in POW camps may still have data worth extracting to inform modern interventions against severe malaria.

Received July 2, 2020. Accepted for publication July 27, 2020.

Published online September 8, 2020.

Note: Supplemental figure appears at www.ajtmh.org.

Acknowledgments: I thank the many unnamed historians, medical librarians, and archivists who have continued to encourage me in the use of old documents and data to understand current medical problems.

Disclaimer: The opinions expressed are those of the author and do not necessarily reflect those of the Australian Defence Force or the U.S. Department of Defense.

Disclosure: The author is an employee of the Australian Defense Organization and a retired U.S. Army medical officer.

Author's addresses: George Dennis Shanks, Australian Defence Force Malaria and Infectious Disease Institute, Enoggera, Australia, and School of Public Health, University of Queensland, Brisbane, Australia, E-mail: dennis.shanks@defence.gov.au.

\section{REFERENCES}

1. White NJ, 2018. Anaemia and malaria. Malar J 17: 371.

2. Leopold SJ, Watson JA, Jeeyapant A, Simpson JA, Phu NH, Hien TT, Day NP, Dondorp AM, White NJ, 2019. Investigating causal pathways in severe falciparum malaria: a pooled retrospective analysis of clinical studies. PLoS Med 16: e1002858.

3. Shanks GD, 2019. Malaria-associated mortality in Australian and British prisoners of war on the Thai-Burma railway 1943-1944. Am J Trop Med Hyg 100: 846-850.

4. Fairley $\mathrm{NH}, 1946$. Malaria in the South-West Pacific, with special reference to its chemotherapeutic control. Med $J$ Aust 2: 145-162.

5. AIF, 1945. 7th Battalion AIF War Diary. Canberra, Australia: Australian War Memorial.

6. AIF, 1945. First Army War Diary. Canberra, Australia: Australian War Memorial.

7. Coates $A, 1946$. Clinical lessons from prisoners of war hospitals in the far east (Burma and Slam). Med J Aust 1: 753-760.

8. Dunlop EE, 1946. Medical experiences in Japanese captivity. $\mathrm{Br}$ Med J 2: 481-486.

9. Long G, 1963. After the Cease Fire. Australia in the War of 1939-1945. Canberra, Australia: Australian War Memorial.

10. Shanks GD, 2017. Malaria-associated mortality in the Australian defence force during the twentieth century. Am J Trop Med Hyg 97: 544-547.

11. Reid J, Wilson T, 1947. Report on nutrition and discussion of the main causes of death, "F" Force, Thailand. J R Army Med Corps 89: 149-165.

12. Wilson T, Reid J, 1949. Malaria among prisoners of war in Siam ("F" Force). Trans R Soc Trop Med Hyg 43: 257-272.

13. Strahan JH, 1948. Quinine by continuous intravenous drip in the treatment of acute falciparum malaria. Trans $R$ Soc Trop Med Hyg 41: 669-676.

14. Walker A, 1963. The Burma-Thailand Railway. Middle East and Far East. Canberra, Australia: Australian War Memorial.

15. Kark R, Aiton H, Pease E, 1946. The nutritional status of Japanese prisoners of war, Burma 1945. Ann Intern Med 25: 266-269.

16. Sazawal S, Black RE, Ramsan M, Chwaya HM, Stoltzfus RJ, Dutta A, Dhingra U, Kabole I, Deb S, Othman MK, 2006. Effects of routine prophylactic supplementation with iron and folic acid on admission to hospital and mortality in preschool children in a high malaria transmission setting: communitybased, randomised, placebo-controlled trial. Lancet 367: 133-143.

17. Maitland K, Babiker A, Kiguli S, Molyneux E, 2012. The FEAST trial of fluid bolus in African children with severe infection. Lancet 379: 613.

18. Maitland K, Olupot-Olupot P, Kiguli S, Chagaluka G, Alaroker F, Opoka RO, Mpoya A, Engoru C, Nteziyaremye J, Mallewa M, 2019. Transfusion volume for children with severe anemia in Africa. N Engl J Med 381: 420-431. 